\title{
Prevalence and factors associated with tobacco use among adults attending selected healthcare facilities in Buffalo City Metropolitan Municipality, South Africa
}

\author{
EO Owolabia ${ }^{*}$, DT Goon ${ }^{a}$, OV Adeniyi ${ }^{b}$ (D) , E Seekoe ${ }^{a}$ and AO Adedokun ${ }^{a}$ \\ ${ }^{a}$ Faculty of Health Sciences, Department of Nursing Science, University of Fort Hare, East London, South Africa \\ ${ }^{b}$ Faculty of Health Sciences, Department of Family Medicine, Walter Sisulu University/Cecilia Makiwane Hospital, East London Hospital complex, \\ East London, South Africa \\ *Corresponding author, email: owolabiomolara101@gmail.com

\begin{abstract}
Aim: Tobacco use increases the risk of cardiovascular disease, premature death and certain cancers. This study investigated the prevalence and determinants of tobacco use among adults in Buffalo City Metropolitan Municipality (BCMM), South Africa. Methods: This study forms part of the cardio-metabolic risk survey carried out at the three largest outpatient clinics in BCMM. This multi-centre cross-sectional survey utilised the relevant items of the WHO STEPwise questionnaire to obtain information on demographic and behavioural characteristics of 1107 participants. A total of 109 participants were excluded as a result of incomplete data. Thus, 998 participants (male $=327$; female $=671$ ) were included in the analysis. Self-reported, current use of any tobacco product was defined as tobacco use while secondary smoking was defined as exposure of non-smokers to environmental tobacco smoke, either at home or in the workplace.

Results: Of all the study participants, 150 (15\%) were current tobacco users and 335 (39.5\%) of the non-smoking participants were exposed to secondary smoking. The majority of the tobacco users were males (70.7\%) compared with females (29.3\%). The commonest form of tobacco use was the manufactured cigarette. The mean age at initiation of smoking was $18.3 \pm 5.1$ and $22.6 \pm 8.0$ years for men and women, respectively. Only male sex $(p=0.000)$, single status $(p=0.003)$, no formal education $(p=0.007)$ and self-employment $(p=0.043)$ were significantly associated with tobacco use.

Conclusion: High prevalence of tobacco use, especially cigarette smoking, in BCMM is worrisome given its strong association with cardiovascular events and cancers. The district health authorities should prioritise smoking cessation measures at the primary health care level.
\end{abstract}

Keywords: adults, Buffalo City Metropolitan Municipality, prevalence, smoking, tobacco use

\begin{abstract}
Introduction
Globally, tobacco use, an established risk factor for cardiovascular diseases and cancer, is a public health threat; it jeopardises human health and also adds a financial burden to the smoker. ${ }^{1}$ Cigarette smoking is a preventable risk factor for mortality globally. ${ }^{2}$ Annually, tobacco use is responsible for 6 million preventable deaths, including 600000 deaths resulting from secondary smoking. ${ }^{3}$ Deaths arising from tobacco use are projected to increase to 8 million by 2030 , if continuous successful actions are not implemented to mitigate the surging growth of smoking habits at the population level. ${ }^{3,4}$
\end{abstract}

According to the World Health Organization, tobacco use is increasing all over the world with a global prevalence of $22 \%$ among adults. ${ }^{5}$ The burden of disease associated with tobacco use, including secondary smoking, has been documented across various developed countries, such as the USA ${ }^{6,7}$ and the UK. ${ }^{8}$ However, a decline in the prevalence of tobacco use has been reported in developed countries with an accompanying increase in low- and middle-income countries (LMICs); where the majority $(80 \%)$ of smokers are now found. ${ }^{9-11}$

South Africa is no exception to the smoking menace. There exists a high prevalence of tobacco use in South Africa. ${ }^{12}$ Tobacco use, including secondary smoking, is a major contributing factor to morbidity and mortality in South Africa, directly accounting for
$8 \%$ of mortality annually and almost a third of mortality amongst men. ${ }^{13,14}$ There is no safe limit for secondary smoking. ${ }^{15}$

Over the past 20 years, a modest reduction in the prevalence of tobacco use has been documented in South Africa following the implementation of comprehensive tobacco control legislation; the number of smokers, however, remains the same as a result of increase in population. ${ }^{16,17}$ Tobacco control legislation includes an increase in cigarette tax, anti-smoking legislation, as well as improved awareness of the dangers of cigarette smoking. ${ }^{16-18}$ Recently, a smoke-free law was also enacted in South Africa, which allows smoking only in designated smoking areas in workplaces and public places..$^{3,19,20}$ Over the past 20 years, data on tobacco use have informed the effectiveness of South Africa's tobacco control strategies. ${ }^{21}$ However, there is a dearth of information on the burden of tobacco use in the Eastern Cape Province. Apart from the National Health Survey conducted in 2012, which included smoking evaluation, ${ }^{21,22}$ limited studies have evaluated the prevalence of tobacco use and secondary smoking among adults in the Eastern Cape Province, South Africa. Proving data on the prevalence and factors associated with tobacco use among specific populations or districts might provide a better understanding of the pattern of tobacco use in such districts and help in developing interventions or health policies. This study was therefore designed to determine the prevalence and factors related to tobacco use among adults in Buffalo City Metropolitan Municipality, South Africa. 


\section{Methodology}

\section{Study settings and participants}

This cross-sectional study forms part of the cardio-metabolic risk factors assessment project in Buffalo City Metropolitan Municipality (BCMM), South Africa. The study screened for cardio-metabolic risk factors among adults attending the largest outpatient clinics in BCMM. The three outpatient clinics were: Cecilia Makiwane hospital, and Nontyatyambo and EmpilweniGompo Community Health Centres, located in the rural and semi-urban communities of the selected district. These health facilities care for a total of 755200 residents in BCMM. ${ }^{23}$ Buffalo City Metropolitan Municipality is situated on the east coast of Eastern Cape Province and it consists of the towns of East London, King William's Town, Bisho and the large townships of Mdantsane and Zwelitsha. The majority (85.1\%) of the residents of BCMM are black Africans, with $6.0 \%$ coloured population, $0.8 \%$ Asian/Indians and $7.7 \%$ whites. $^{23}$

\section{Sample and sampling technique}

The appropriate sample size was estimated using the following formula:

$N=(Z 1-\alpha) 2 *(P(1-P)) / D 2$

Where $\mathrm{Z}$ is the confidence level, $\mathrm{P}$ is the expected proportion of individuals with cardio-metabolic risk factors, and $D$ is the margin of error. $P$ was set at 0.40 and $D$ at 0.05 . The calculation was performed at the $95 \%$ confidence level. The required sample size per study site was 369 participants and a total of 1107 participants were included in the study. All ambulatory individuals (both patients and relatives) who fulfilled the inclusion criteria and were attending the study settings during the period of study were conveniently recruited into the study by the researcher. This study was conducted in April and May 2016. Participants were included if they were 18 years and above and excluded if debilitated, pregnant, breastfeeding or have psychiatric disorders in such a manner that obtaining information or anthropometric measurements seemed difficult. One hundred and nine participants were excluded from the study as a result of incomplete data. Thus, a total of 998 adults were included in the data analysis.

\section{Study instrument}

The participants were interviewed using the previously validated WHO STEPwise questionnaire, ${ }^{24}$ which comprises three major items: demographic and behavioural data, and measurements. The instrument was adapted locally and a pilot study, which included 20 participants at one of the sites, was conducted to validate its suitability in the local setting as well as to test the effectiveness of the research process. However, the result of the pilot study was not included in the analysis.

\section{Study procedure}

Trained research assistants collected relevant data on demographic and behavioural characteristics using the WHO STEPwise questionnaire. Demographic variables included items on sex, age, marital status, level of education, employment status and average monthly income. Participants' average self-reported monthly income, level of education and employment status were assessed. Participants earning R2000 or less per month were categorised as low-income earners and middle-income earners if they earned more than R2000. Their level of education was determined by self-reporting of the highest grade level attained in school and was categorised as having no formal education, primary (grade 1-7), secondary (grade 8-12) or tertiary (post-secondary). Participants were defined as unemployed if they reported that they were not employed in both formal and informal sectors.

Tobacco use was defined as self-reported current use (in the past month) of any tobacco product while secondary smoking was defined as self-reported exposure within the past week to cigarette or any tobacco smoke among non-smokers, either at the workplace or at home. Smoking status was defined by the question 'On the day/days that you smoked cigarettes during the past 30 days, how many cigarettes did you smoke, on average?'. Tobacco users were categorised as low rate (smoke at least five cigarette sticks per day); light rate (smoke between six to nine cigarette sticks per day) and high rate (smoke more than 10 cigarette sticks per day). ${ }^{25,26}$

\section{Ethical considerations}

Ethical approval was obtained from the University of Fort Hare ResearchEthics Committee (Reference number, GOO061SOLO01). Afterwards, permission to conduct the study was obtained from the Eastern Cape Department of Health, the management of the Sub-District Department of Health in Buffalo City Metropolitan Municipality and, finally, the management of the respective health facilities. An information sheet detailing the nature, purpose and the procedure of the study was given to each participant. Each participant gave written, informed consent for his/her voluntary participation in the study. The participants' right to privacy, confidentiality and anonymity were taken into consideration.

\section{Statistical analysis}

Descriptive and inferential statistics were used for the data analysis. Frequencies ( $n$ ) and proportions (\%) were reported for categorical variables. The associations between the demographic variables and smoking were assessed through bivariate analysis. The Statistical Package for Social Science (SPSS) version 21.0 was used for the data analysis (IBM Corp, Armonk, NY, USA). A $p$-value $<0.05$ was considered statistically significant.

\section{Results}

\section{Demographic characteristics of the participants}

Table 1 presents the demographic characteristics of the participants. A total of 998 participants were included in the analysis. The mean age of participants was 42.6 (SD \pm 16.5 ), with the age range being 18 to 75 years. The majority of the participants were black (98.1\%), female (67.8\%), single (63.9\%) and had at least a grade 8 level of education (69.7\%). About half of the participants had no means of income $(44.6 \%)$ and were unemployed (47.7\%), while only a few $(7.5 \%)$ participants earned above R5000 monthly.

As shown in Figures 1-3, $150(15 \%)$ of the participants were tobacco users. Of these, the majority 132 (88.0\%) were daily smokers, and 97 (67.4\%) consumed fewer than five cigarettes per day. The mean age of smoking initiation for males was $18.3 \pm 5.1$ and $22.6 \pm 8.0$ for females. Of the 143 participants who reported the type of tobacco product used, $113(78.3 \%)$ reported using manufactured cigarettes, 13 (9.1\%) used hand-rolled cigarettes, $11(7.7 \%)$ used pipes, 5 (13.5\%) used manufactured and handrolled cigarettes and 2 (1.2\%) reported using snuff.

\section{Secondary smoking}

About $40 \%(n=335)$ of the non-smoking participants were exposed to passive smoking either at home or in the workplace. 
Table 1: Demographic characteristics of the participants by sex

\begin{tabular}{|c|c|c|c|}
\hline Variables & $\begin{array}{c}\text { Male, } n=321 \\
n(\%)\end{array}$ & $\begin{array}{c}\text { Female, } n=677 \\
n(\%)\end{array}$ & $\begin{array}{c}\text { Total, } n=998 \\
n(\%)\end{array}$ \\
\hline \multicolumn{4}{|l|}{ Age group (years) } \\
\hline $18-25$ & $40(12.5)$ & $143(21.1)$ & $183(18.3)$ \\
\hline $26-35$ & $74(23.1)$ & $149(22.0)$ & $223(22.3)$ \\
\hline $36-45$ & $67(20.9)$ & $116(17.1)$ & $183(18.3)$ \\
\hline $46-55$ & $57(17.8)$ & $110(16.2)$ & $167(16.7)$ \\
\hline $56-65$ & $41(12.8)$ & 99 (14.6) & $140(14.0)$ \\
\hline$\geq 66$ & $42(14.1)$ & $60(8.9)$ & $102(10.2)$ \\
\hline \multicolumn{4}{|l|}{ Level of education } \\
\hline $\begin{array}{l}\text { No formal school- } \\
\text { ing }\end{array}$ & $62(19.3)$ & $84(12.4)$ & $146(14.6)$ \\
\hline Grade 1-7 & $57(17.8)$ & 99 (14.6) & $156(15.6)$ \\
\hline Grade 8-12 & $17(53.3)$ & $409(60.4)$ & $580(58.1)$ \\
\hline Tertiary & $31(9.7)$ & 85 (12.6) & $116(11.6)$ \\
\hline \multicolumn{4}{|c|}{ Monthly income (Rand) } \\
\hline No income & $134(41.7)$ & $300(44.3)$ & $445(44.6)$ \\
\hline R150-2 000 & $89(27.7)$ & $248(36.6)$ & $326(32.7)$ \\
\hline R2 001-5 000 & $74(23.1)$ & $100(14.8)$ & $174(17.4)$ \\
\hline R5 001 and above & $24(7.5)$ & $29(4.3)$ & $53(5.3)$ \\
\hline \multicolumn{4}{|l|}{ Marital status } \\
\hline Single & $193(60.3)$ & $444(65.6)$ & $637(63.9)$ \\
\hline Married & $115(35.9)$ & $185(27.3)$ & $300(30.1)$ \\
\hline Separated & $1(0.3)$ & $5(0.7)$ & $6(0.6)$ \\
\hline Divorced & $9(2.8)$ & $13(1.9)$ & $22(2.2)$ \\
\hline Widowed & $2(0.6)$ & $30(4.4)$ & $32(3.2)$ \\
\hline \multicolumn{4}{|l|}{ Racial group } \\
\hline Black & $313(97.5)$ & $666(98.4)$ & $979(98.1)$ \\
\hline Coloured & $8(2.8)$ & $9(1.3)$ & $17(1.7)$ \\
\hline White & $0(0.0)$ & $2(0.3)$ & $2(0.2)$ \\
\hline \multicolumn{4}{|l|}{ Type of employment } \\
\hline $\begin{array}{l}\text { Government } \\
\text { employee }\end{array}$ & $30(9.3)$ & $33(4.9)$ & $63(6.3)$ \\
\hline $\begin{array}{l}\text { Non-government } \\
\text { employment }\end{array}$ & $98(30.5)$ & $133(19.7)$ & $231(23.2)$ \\
\hline Self-employment & $30(9.3)$ & $32(4.7)$ & $62(6.2)$ \\
\hline Students & $19(5.9)$ & $80(11.8)$ & $99(9.9)$ \\
\hline Unemployed & $115(24.2)$ & $361(53.4)$ & $476(47.7)$ \\
\hline Retired & $29(9.0)$ & $37(5.5)$ & $66(6.6)$ \\
\hline
\end{tabular}

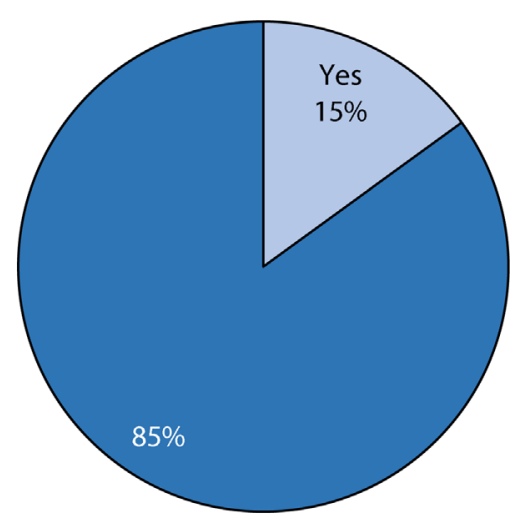

Figure 1: Prevalence of smoking.
As indicated in Figure 4, 74.9\% $(n=251)$ of non-smoking participants who were exposed to cigarette smoke either at home or in their workplace were females.

As shown in Table 2, only sex $(p=0.000)$, marital status $(p=0.003)$, level of education $(p=0.007)$ and employment status $(p=0.043)$ were significantly associated with tobacco use. Male participants used tobacco products five times more (33.0\%) than their female counterparts (6.5\%). Participants who had never married used tobacco products more $(17.6 \%)$ than their married counterparts (10.7\%). Self-employed individuals had the highest prevalence of tobacco use (21\%) compared with students (8.1\%) and the retired participants $(9.1 \%)$. Also, participants with no form of education had the highest prevalence of tobacco use $(21.0 \%)$ compared with those with tertiary levels of education (13.8\%).

\section{Discussion}

This study assessed the burden of tobacco use among adult residents in BCMM, South Africa. The study found a prevalence of tobacco use of $15 \%$ among the participants and $88.7 \%$ of the tobacco users smoked daily. High prevalence of tobacco use, including secondary exposure, in this setting is worrisome, given the fact that cigarette smoking is an independent and significant risk factor for cardiovascular disease, premature death and certain cancers. ${ }^{5,27}$ Our results might be due to the effect of globalisation and epidemiological transitions in rural and semiurban BCMM.

The World Health Organization reported a global increase in cigarette smoking, particularly in the African region. ${ }^{5}$ The prevalence found in this study was slightly lower than the reported national prevalence for tobacco use: $18.1 \%, 16.9 \%$ and $17.6 \%$ in 2010, 2011 and 2012, respectively. ${ }^{16,21,22}$ However, our result was similar to a report by Waweru et al. ${ }^{28}$ which found a smoking prevalence of $15 \%$ among adults in Johannesburg, South Africa. In South Africa, the prevalence of smoking was reported to have modestly reduced between 2004 and 2014, from $24 \%$ to $20 \%$; however, there was no reduction in the number of smokers, due to population growth. ${ }^{18}$ The findings of the present study further substantiate the documented decrease in the prevalence of smoking in South Africa. This is commendable; however, continuous monitoring is required to sustain the effectiveness of tobacco control policies in this country.

The prevalence of smoking recorded in this study was lower than those reported in some other developing countries. For instance, the prevalence rates in India and Chile ranged from $34.6 \%$ to $45.4 \%{ }^{29,30}$ In North Africa and eastern Mediterranean countries, such as Morocco and Lebanon, the prevalence of smoking was $15.3 \%$ and $53.9 \%$, respectively. ${ }^{31}$ The prevalence of smoking in Nigeria as reported by various studies ranged from $3.83 \%$ to $30 \%$, varying among different settings, ${ }^{32-35}$ but with the majority of settings showing a prevalence above $20 \%$. Rates lower than those reported in this study have been documented in Ghana, where rates of smoking ranged from $0.3 \%$ to $3.8 \%$ in 2009 and have witnessed no significant changes over the last three decades. $^{36,37}$ The significant difference in the prevalence of smoking between Ghana and the other African countries might be as a result of the traditionally low rate of tobacco use in Ghana. Ghana has been reported to have the lowest rate of tobacco use in Africa. ${ }^{38}$

More than half (64.4\%) of the smokers in this study were low-rate smokers (consuming fewer than five cigarettes per day). Smoking 


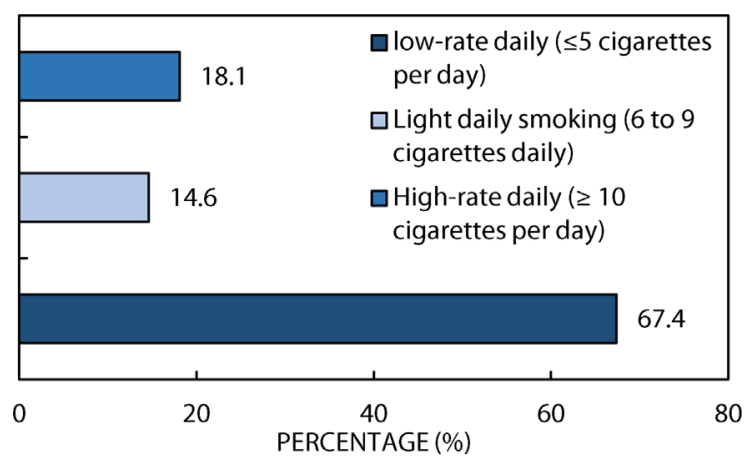

Figure 2: Smoking categories of participants.

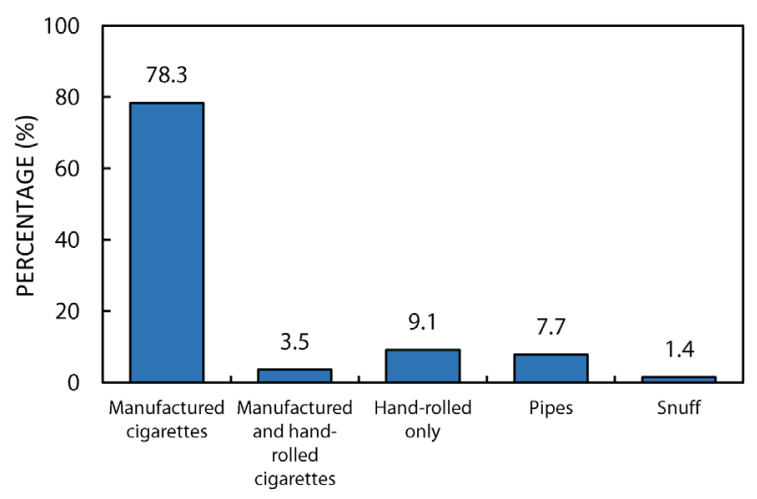

Figure 3: Types of tobacco products used by participants.

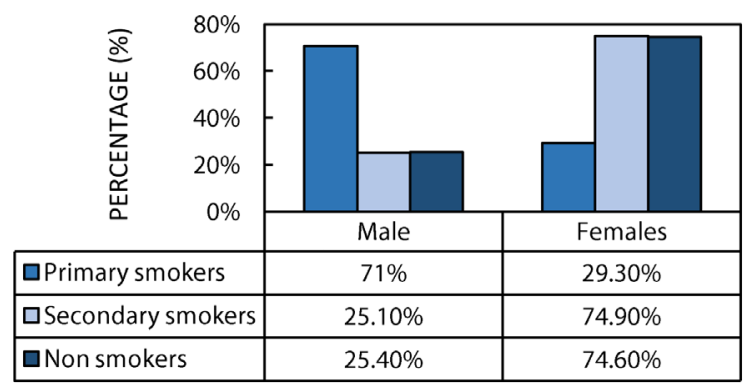

Figure 4: Smoking categories distributed by sex.

cessation measures should be considered in all individuals using tobacco products given that even less than five cigarettes per day is associated with increased cardiovascular risks. ${ }^{39}$ The most common form of tobacco product used by the participants was the manufactured cigarette. This is not surprising as this form of cigarette is easily accessible. The use of other forms of tobacco such as pipes and snuff seems low among the study participants. This might be as a result of the sampling technique adopted for the study as a higher rate of use has previously been documented among the rural and semi-urban communities of South Africa. ${ }^{40}$ Yet, this should also be a source of concern as smokeless tobacco sources seen as alternatives, particularly snuff, have been associated with a higher addictive effect and high risk for cardiovascular diseases and some forms of cancer. ${ }^{41}$ Often, little emphasis is laid on these forms of tobacco use compared with manufactured cigarette. ${ }^{41}$ The use of these products should be completely discouraged, particularly by the healthcare practitioners involved in behavioural counselling at the primary health care level. Consistent with Mujuzi's study, ${ }^{12}$ the age-of initiation of tobacco use in this study was $18.3 \pm 5.1$ years and $22.6 \pm 8.0$ years for male and female, respectively. Also, the current age of restriction for the sale of tobacco in South Africa is 18 years..$^{43}$ Carlson et al. ${ }^{44}$ affirm that cigarette smoking is often commenced in childhood or adolescence, the age range of study participants within which the age of initiation of tobacco use fell.

In addition, 39.5\% of the non-smoking participants were either exposed to secondary smoke at home or at work, with the highest rate of exposure found amongst women (74.9\%). The high rate of secondary smokers in this study corroborated the result of the high rate of active smoking within the same setting. Women tended to be more often at the receiving end of the smoking of others, which is of concern in view of the risks associated with foetal exposure during pregnancy such as growth restrictions and foetal losses. Also, exposure to secondary smoke has more detrimental effects than assumed as it has about $70 \%$ of the adverse health outcome of active smoking. ${ }^{45}$ This result supports the global call for stringent measures for smoking cessation at the population level. Women whose partners smoke are mostly exposed to secondary smoke even when they do not smoke themselves. This shows that almost half of the non-smoking participants are also at risk of developing cardiovascular disease, as secondary smoking has been implicated in increasing cardiovascular risk by $25-30 \%$ and no safe limit has been established. ${ }^{45}$ Likewise, Xu et al. ${ }^{46}$ also reported higher exposure to secondary smoke at home among women. The higher rate found among women is expected. In patriarchal societies such as South Africa, the smoking habits of males may account for unwilling and unavoidable exposure to smoke of female non-smokers. There is a need to urgently control the exposure of women in view of a slightly more detrimental effect of smoking on their cardiovascular system compared with men. ${ }^{47}$ In addition to the second-hand exposure among women, there is also an increase in uptake of smoking among young women, which might be a resultant effect of urbanisation, and socioeconomic and political emancipation. Thus, the overall risk of morbidity and mortality from smoking may increase, necessitating targeting this group for intensified anti-smoking interventions.

Sex, marital status, level of education and employment status were significantly associated with tobacco use. The prevalence of tobacco use among men was five times greater than that recorded among females. This finding corroborated the findings of other studies. 1,16,21,31 Smoking is considered to be socially acceptable among men compared with women in the majority of South African communities, thus accounting for the higher prevalence of smoking recorded among men. ${ }^{48,49}$

The prevalence of smoking was higher among participants who were never married compared with those who were married. Marriage often comes with responsibilities and married participants are more likely to be restricted in their ability to purchase cigarettes. Such restraints were less prevalent among single and unmarried individuals.42,50,51 Employment status and level of education were significantly associated with smoking. Participants with no formal education as well as those who were self-employed had a higher prevalence of cigarette smoking. This was contrary to the report of Yoon and Bernell, ${ }^{52}$ who contend that self-employed individuals were less likely to smoke compared with those who were employed. Du and Leigh ${ }^{53}$ stated that the higher the income, the less likely the risk of smoking. This was affirmed by the lower prevalence reported among students and retired individuals, who are dependent and also 
Table 2: Association between demographic characteristics and smoking

\begin{tabular}{|c|c|c|c|c|c|}
\hline Variables & Smoke & $\begin{array}{l}\text { Do not } \\
\text { smoke }\end{array}$ & $\mathrm{RR}$ & $\mathrm{Cl}(95 \%)$ & $p$-value \\
\hline \multicolumn{6}{|l|}{ Age (years) } \\
\hline $18-25$ & $28(15.3)$ & $155(84.7)$ & & & 0.290 \\
\hline $26-35$ & $38(17.0)$ & $185(83)$ & & & \\
\hline $36-45$ & $24(13.1)$ & $159(86.9)$ & & & \\
\hline $46-55$ & $32(19.2)$ & $135(80.8)$ & & & \\
\hline $56-65$ & $18(12.9)$ & $122(87.1)$ & & & \\
\hline Above 65 & $10(9.8)$ & $84.8(85)$ & & & \\
\hline \multicolumn{6}{|l|}{ Sex } \\
\hline Male & $106(33.0)$ & $215(67.0)$ & 7.1 & $4.8-7.4$ & $0.000^{*}$ \\
\hline Female & $44(6.5)$ & $633(96.5)$ & & & \\
\hline \multicolumn{6}{|l|}{ Income (Rand) } \\
\hline $\begin{array}{l}2000 \text { and } \\
\text { below }\end{array}$ & $45(12.6)$ & $312(87.4)$ & 0.67 & $0.4-1.1$ & 0.061 \\
\hline $\begin{array}{l}2001 \text { and } \\
\text { above }\end{array}$ & $40(17.6)$ & $187(82.4)$ & & & \\
\hline \multicolumn{6}{|l|}{ Marital status } \\
\hline Never married & $112(17.6)$ & $525(82.4)$ & 1.8 & $1.2-2.7$ & $0.003^{*}$ \\
\hline Ever married & $35(10.7)$ & $293(89.3)$ & & & \\
\hline \multicolumn{6}{|l|}{ Level of education } \\
\hline $\begin{array}{l}\text { No formal } \\
\text { schooling }\end{array}$ & $31(21.1)$ & $115(78.8)$ & - & - & $0.007^{*}$ \\
\hline Grade 1-7 & $27(17.3)$ & $129(82.7)$ & & & \\
\hline Grade 8-12 & $76(13.1)$ & $504(86.9)$ & & & \\
\hline Tertiary & $16(13.8)$ & $100(86.2)$ & & & \\
\hline \multicolumn{6}{|c|}{ Employment status } \\
\hline $\begin{array}{l}\text { Government } \\
\text { employee }\end{array}$ & $11(17.5)$ & $52(82.5)$ & - & - & $0.043^{*}$ \\
\hline $\begin{array}{l}\text { Non-govern- } \\
\text { ment employee }\end{array}$ & 45 (19.5) & $186(80.5)$ & & & \\
\hline Self-employed & $13(21.0)$ & $49(79.0)$ & & & \\
\hline Student & $8(8.1)$ & $91(91.9)$ & & & \\
\hline Unemployed & $67(14.1)$ & 409 (85.9) & & & \\
\hline Retired & $6(9.1)$ & $60(90.9)$ & & & \\
\hline
\end{tabular}

*Statistically significant at $p \leq 0.05$.

have multiple sources of income. Such sources of income include pensions and old people's social grants for the elderly, as obtainable in South Africa, and allowances for students. This also explained why participants with no formal education had a higher smoking prevalence compared with those with a tertiary level of education. Similarly, low level of education had been reported to be associated with a higher prevalence of smoking. ${ }^{54}$ Thus, the higher prevalence of smoking found among the participants with no formal education was not surprising. The higher prevalence of smoking found among the self-employed could be because they operate in a private work environment, which makes it less difficult to enforce anti-smoking regulations.

\section{Strength and limitations}

Although a standardised procedure and questionnaire was utilised in this study, the limitations of this study cannot be ignored. The cross-sectional design of the study could not enable us to establish correlations between variables. Also, selfreporting and convenience sampling of participants might have introduced some bias or led to under-reporting of the true prevalence of tobacco use, particularly those types other than the manufactured cigarette. Thus, the findings might not be reflective of the national South African demography. Also, it is possible that sampling patients aged 18 years and older might have led to under-reporting of the prevalence of tobacco use in the settings as tobacco use has been reported to be increasing among young people. We also did not obtain data on the duration of cigarette smoking (pack year assessment was difficult). However, the large sample size gave credence to the findings of this study. In addition, this study provided useful epidemiological data to assist district health managers in crafting effective interventions to be implemented at the primary health care level across the district.

\section{Conclusion}

A high proportion of adult residents of BCMM still smoke cigarettes actively despite the implementation of tobacco control policies in South Africa. A significant proportion of individuals living in the region, especially women in the reproductive age groups, are exposed to secondary smoke indoors or in the workplace. Thus, women should be targeted for intensified anti-smoking interventions. District health policies on non-communicable diseases should also incorporate smoking cessation measures at the primary health care and population levels. The current ongoing behavioural health counselling introduced at primary health care centres should be intensified and smokers should also be helped to quit using evidence-based clinical guidelines. Strengthening tobacco-control policies and promoting a comprehensive smoke-free law that prohibits smoking in all indoor areas with no exceptions might result in decreased smoking in the next decade.

\section{Conflicts of interest - None declared.}

Acknowledgement - The authors are grateful to the National Research Foundation and the Health and Welfare Sector Education and Training Authority, South Africa for the study grant given to EOO for executing the Master's Degree project from which the current study emanates.

\section{ORCID}

\section{OV Adeniyi (D) http://orcid.org/0000-0003-0216-6701}

\section{References}

1. Zhang D, Cao J, Dong Z, et al. Science Direct Prevalence of active and passive tobacco smoking among Beijing residents in 2011. Chr Dis Transl Med. 2016;2:120-8.

2. World Health Organization. Tobacco. Geneva, Switzerland. 2016. Available from: http://www.who.int/nmh/publications/fact_sheet tobacco_en.pdf.

3. WHO Report on the Global Tobacco Epidemic. Enforcing Bans on Tobacco Advertising. Geneva: Promotion and Sponsorship. World Health Organization; 2015.

4. World Health Organization. Physical activity. Health Topics. 2016. [cited 2016 July 9]. Available from: http://www.who.int/topics/ physical_activity/en/.

5. World Health Organization. Global status report on noncommunicable diseases 2015: attaining the nine global concommunicable diseases targets; a shared responsibility. Geneva: World Health Organization; 2015.

6. American Lung Association. Health effects of smoking. Smoking facts. 2016. [cite 2016 June 18]. Available from: http://www.lung.org/ stop-smoking/smoking-facts/health-effects.html?

7. Jha P, Ramasundarahettige C, Landsman V, et al. 21 st-Century Hazards of Smoking and Benefits of Cessation in the United States. N Engl J Med 2013;368(4):341-350. https://doi.org/10.1056/NEJMsa1211128 
8. Pirie K, Peto R, Reeves GK, et al. The 21 st century hazards of smoking and benefits of stopping : a prospective study of one million women in the UK. Lancet 2013;381:133-41. https://doi.org/10.1016/S01406736(12)61720-6

9. Eriksen M, MacKay J, Ross H. The Tobacco World Atlas, 4th ed. World Lung Foundation and American Cancer Society, 2012. [cited 2013 Oct, 1]. Available from: http://www.tobaccoatlas.org.

10. Giovino GA, Mirza SA, Samet JM, et al. Tobacco use in 3 billion individuals from 16 countries: An analysis of nationally representative cross-sectional household surveys. Lancet 2012;380(9842):668-79. https://doi.org/10.1016/S0140-6736(12)61085-X

11. Murray CJL, Lopez AD. Measuring the Global Burden of Disease. N Engl J Med. 2013;369:448-57. https://doi.org/10.1056/NEJMra1201534

12. Mujuzi JD. Smoking in the workplace in South Africa: Law and practice relating to the rights and obligations of employers and employees. SAJBL 2010;3(2):79-83.

13. Health 24. Law catches up with smokers. Stop Smoking. 2009. [cited 2016 June 21]. Available from: http://www.health24.com/Lifestyle/ Stop-smoking/Law-catches-up-with-smokers-20120721.

14. Van Zyl-Smit RN, Allwood Bc, Stickells D, et al. South African tobacco smoking cessation clinical practice guideline. SAMJ, 2013; 103(11):833.

15. Ayo-Yususf O, Olufajo O, Agaku IT. Exposure to secondhand smoke and voluntary adoption of smoke-free home and car rules among non-smoking South African adults. BMC Public Health 2014;14:580. https://doi.org/10.1186/1471-2458-14-580

16. Ayo-yusuf OA, Olutola BG. 'Roll-your-own' cigarette smoking in South Africa between 2007 and 2010. BMC Public Health 2013;13:597. https://doi.org/10.1186/1471-2458-13-597

17. Vellios N, Van WC. Determinants of regular smoking onset in South Africa using duration analysis. BMJ Open 2016;6:0111076.

18. Zuma ND. A comprehensive, health-promotion approach to tobacco control. SAMJ 2013;103(11):1.

19. Avenant R. Tobacco control legislation. Cape Town: The Cancer Association of South Africa; 2015.

20. Baleta A. South African's Health Minister wins anti-smoking court battle. Lancet 1998;352:890.

21. Reddy P, Zuma K, Shisana O, Jonas K, Sewpaul R. Prevalence of tobacco use among adults in South Africa: Results from the first South African National Health and Nutrition Examination Survey. SAMJ 2015;105(8):648-55. https://doi.org/10.7196/SAMJnew.7932

22. Shisana O, Labadarios D, Rehle T, et al. The South African national health and nutrition examination survey SANHANES-1. 1st ed. Cape town: HSRC press; 2013.

23. Statistics South Africa. South African statistics, South Africa. 2011; 1-190. Available from: http://www.statssa.gov.za/publications/ SAStatistics/SAStatistics2011.pdf.

24. World Health Organization. Distribution: general steps: A framework for surveillance The WHO STEPwise approach to Surveillance of noncommunicable diseases (STEPS), Geneva: Author. 2003. Available from: www.who.int/...surveillance/.../steps_framework_dec03.pdf.

25. Robertson L, Losua E, McGee R, Hancox RJ. Non-daily, low-rate daily, and high-rate daily smoking in Young Adults: A 17-year follow up. Nicotine Tob Res. 2016;18(5):943-9. https://doi.org/10.1093/ntr/ntv167

26. Staton CA, Papadonatos G, Llyod-Richardson EE, et al. Consistency of self-reported smoking over a 6-year interval from adolescence to young adulthood. Addiction. 2007;102:1831-9. https://doi.org/10.1111/add.2007.102.issue-11

27. Mancia G, Fagard R, Narkiewicz K, et al. ESH/ESC guidelines for the management of arterial hypertension: the Task Force for the Management of Arterial Hypertension of the European Society of Hypertension (ESH) and of the European Society of Cardiology (ESC). Blood pressure 2013;22:193-278. doi:10.3109/08037051.2013.812549. PMID: 23777479.

28. Waweru P, Anderson R, Steel H, Venter WDF, Murdoch D, Feldman C. The prevalence of smoking and the knowledge of smoking hazards and smoking cessation strategies among HIV- positive patients in Johannesburg. South Africa. SAMJ 2013;103(11):858-60.
29. Champagne BM, Sebrié EM, Schargrodsky $H$, Pramparo $P$, Boissonnet C, Wilson E. Tobacco smoking in seven Latin American cities: the CARMELA study. Tobacco Control 2010;19(6): 457-62. https://doi.org/10.1136/tc.2009.031666

30. Gupta B. Burden of Smoked and Smokeless Tobacco Consumption in India - Results from the Global adult Tobacco Survey India (GATSIndia) - 2009-2010. A Pac J Can Prev. 2013;14(5):3323-29.

31. Khattab A, Javaid A, Iraqi G, et al. Smoking habits in the Middle East and North Africa: Results of the BREATHE study. Res Med 2012;106(S2):S16S24. https://doi.org/10.1016/S0954-6111(12)70011-2

32. Desalu OO, Oluboyo PO, Olokoba AB, et al. Prevalence and determinants of tobacco smoking among HIV patients in North Eastern Nigeria. Afr J Med Sci. 2009;38(2):103-8.

33. Hussain N, Akande M, Adebayo E. Prevalence of cigarette smoking and knowledge implications among Nigerian soldiers of its health. $E$ Afr J Public Health 2010;7(1):81-3.

34. Odeyemi KA, Osibogun A, Akinsete AO, Sadiq L. The Prevalence and Predictors of Cigarette Smoking among Secondary School Students in Nigeria. N Postgraduate Med. J. 2009;16(1):40-5.

35. Salaudeen A, Akande T, Musa O. Cigarette smoking prevalence and awareness of health problems of tobacco use among students of colleges of education in a North-Central State of Nigeria. Nig Med Pract 2009;55:6.

36. Addo J, Smeeth L, Leon DA. smoking patterns in ghanaian civil servants: changes over three decades. Intl J Env Res Pub Health 2009;6:200-8. https://doi.org/10.3390/ijerph6010200

37. Lewis S, Mcneill A, Gilmore A, Britton J. Smoking uptake and prevalence in Ghana. Tobacco Control 2009;18:365-70.

38. Pampel F. Tobacco use in sub-Sahara Africa: estimates from the demographic health surveys. Soc Sci Med. 2008;66:1772-83. https://doi.org/10.1016/j.socscimed.2007.12.003

39. U.S Department of Health and Human Service. The health consequences of smoking -50 Years of progress: a report of the surgeon general. Atlanta, GA: Author. 2014.

40. Peer N, Bradshaw D, Laubscher R, Steyn K. Trends in adult tobacco use from two South African demographic surveys conducted in 1998 and 2003. SAMJ 2009;99:744-9.

41. Omole OA, Ogunbanjo GA, Ayo-Yusuf OB. Review of alternative practices to cigarette smoking and nicotine replacement therapy: how safe are they? S Afr FAm Pract. 2011;53(2):154-60. https://doi.org/10.1080/20786204.2011.10874077

42. Schane RE, Ling PM, Glantz SA. Health effects of light and intermittent smoking: A review. Circ. 2010;121(13):1518-22. https://doi.org/10.1161/CIRCULATIONAHA.109.904235

43. SA Health. Smoking, the rules and regulation. Prot Public Health 2013:1-2. [cited 2016 Dec 12]. Available from: http://www.sahealth. sa.gov.au/wps/wcm/connect/Public+Content/SA+Health+Internet/ Protecting+public+health/Smoking+the+rules+and+regulations/.

44. Carson KV, Brinn MP, Labiszewski NA, et al. Interventions for tobacco use prevention in Indigenous youth. Cochrane Database Sys Rev. 2012; 8:CD009325.

45. U.S Department of Health and Human Services. The health consequences of involuntary exposure to tobacco smoke: A Report of the Surgeon General. Atlanta, GA: Author. 2006.

46. Xu Z, Han H, Zhuang $C$, et al. Tobacco use and exposure to second-hand smoke among urban residents: A community-based investigation. Int J Endocr. 2015;12:9799-808.

47. Konstantopoulou SS, Behrakis PK, Lazaris AC, NicolopoulouStamati P. Indoor air quality in a bar/restaurant before and after the smoking ban in Athens Greece. Sci Total Environ 2014;476: 136-43. https://doi.org/10.1016/j.scitotenv.2013.11.129

48. Huxley RR, Woodward M. Cigarette smoking as a risk factor for coronary heart disease in women compared with men: a systematic review and meta-analysis of prospective cohort studies. Lancet 2011;6736(11):60781-2.

49. Reddy $P$, James $S$, Sewpaul $R$, et al. A decade of tobacco control: The South African case of politics, health policy, health promotion and behaviour change. SAMJ 2013;103(11):835-40. https://doi.org/10.7196/samj.6910 
50. Kim S. Smoking prevalence and the association between smoking and sociodemographic factors using the Korea National Health and Nutrition Examination Survey Data, 2008 to 2010. Tobacco Use Insight 2012;5:17-26. https://doi.org/10.4137/TUI

51. LindstromM.Socialcapital,economicconditions, maritalstatusanddaily smoking: a population-based study. Public Health 2010;124(2):71-7. https://doi.org/10.1016/j.puhe.2010.01.003

52. Yoon J, Bernell SL. The effect of self-employment on health, access to care, and health behavior. Health 2013;5(12):2116-27. https://doi.org/10.4236/health.2013.512289
53. Du J, Leigh P. Effects of wages on smoking decisions of current and past smokers. An of Epidemiol 2015; 25(8):575-582.e1. https://doi.org/10.1016/j.annepidem.2015.03.016

54. Termsirikulchai L, Benjakul S, Kengganpanich M, et al. Thailand tobacco control country profile. Bangkok: Tobacco Control Research and Knowledge Management Center, Mahidol University. 2008 Available from: http://www.who.int/fctc/reporting/annextwothai. pdf.

Received: 25-02-2017 Accepted: 06-06-2017 